\title{
Fly a Rocket! Undergraduate rocket science
}

\author{
Alondra Solá and P. Solano-López \\ EIATA, Universidad Rey Juan Carlos \\ Madrid, Spain \\ a.solam.2017@alumnos.urjc.es, pablo.solano@urjc.es
}

\begin{abstract}
The Fly a Rocket! programme is an intensive training course in rocket design and construction aimed at undergraduate students. The open-ended assignments, as well as the hands-on campaign, were the perfect lab-test for an engineering project. Activities like this prepare students for the problems faced in professional life, in commercial or research careers, and provide an active transfer between universities and institutions like ESA or sector companies.
\end{abstract}

Keywords- active transfer; Andoya Space Center; education; ESA Education; NAROM

\section{INTRODUCTION}

The Fly a Rocket! (FaR!) programme is a hands-on training and learning opportunity for undergraduate students pursuing science and engineering degrees.

The programme consists of a pre-study course followed by a rocket campaign at the Andøya Space Center (ASC). One of the authors (Alondra Solá) participated in the second cycle of the FaR! programme, where 23 students with 14 different nationalities gathered to prepare and launch a rocket into the Arctic airspace. It was both an intensive training course in rocket design and construction and a summer camp for space enthusiasts. The immersive, comprehensive experience made a strong impact on her: academically, personally, and professionally.

This paper will give a summary of the FaR! programme and the personal experience of a participant at the campaign. In addition, as members of the academic community (undergraduate student and professor), we the authors present our views of this programme.

The programme is organized by the ESA Education Office, the Norwegian Center for Space Related Education (NAROM) and the Norwegian Space Agency. The campaign took place at the Andøya Space Center, $310 \mathrm{~km}$ north of the Arctic Circle.

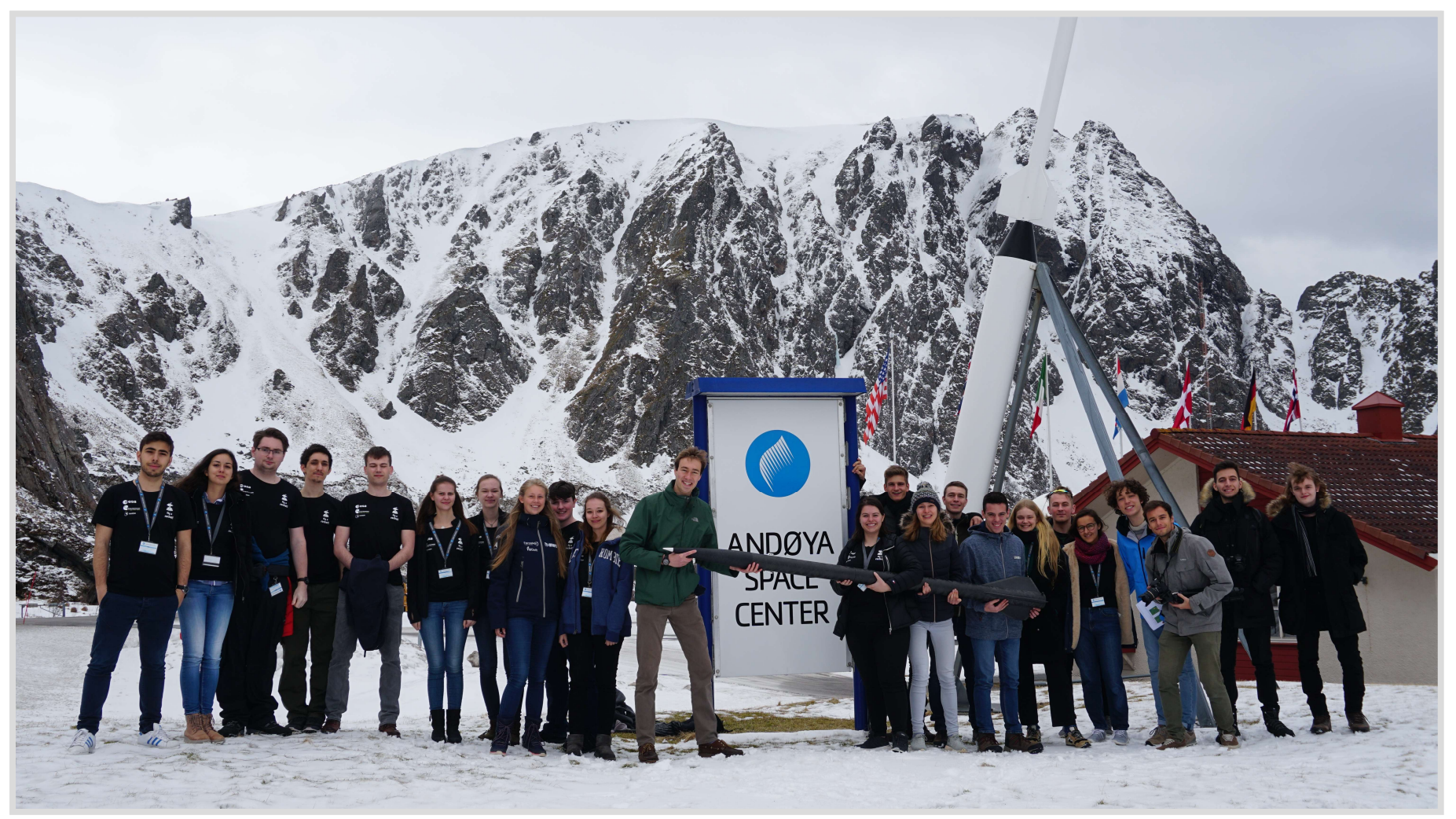

Fig. 1. The Fly a Rocket! 2018-2019 participants at the Andøya Space Center. Source: ESA [1] 
FaR! was aimed at undergraduate students in the first two years of their undergraduate education. Applications were open to students from all ESA member states, as well as Canada and Slovenia

The 23 participants came from space-related backgrounds such as Aerospace Engineering or Space Sciences, as well as other degrees with intrinsic applications such as Physics, Biology, or Natural Sciences. Each participant brought their cultural and technical background to the table, and through this fascinating exchange a competent team was formed.

\section{PRE-STUDY AND ASSIGMENTS}

The pre-study course was designed to make sure all the students had a mastery of the fundamentals of rocket science, so that they could take full advantage of their time at ASC. It also helped the organizers of the programme to estimate the students' technical level, as well as their familiarity with the theory and the software they would need during the campaign.

NAROM prepared extensive pre-study material, available online, about rocket engines, aerodynamics, satellites, and orbital dynamics. The contents also introduced the particular rocket that would be launched (the Mongoose 98) and explained preliminary simulations of its flight.

In addition to this study material, the students were asked to complete two assignments. The problems were varied and required both meticulous study of the subject matter and research on other rockets and past missions. The scope was much broader than what university assignments are usually limited to, and creativity was a must. In many cases the participants were not asked to provide "the right answer" but rather the argument that best supported the conclusions presented.

For example, one problem was to create a simulation of the student rocket's flight. Several approaches could be taken to simplify this problem. Mass could be assumed constant (as initial weight, average weight, or dry weight), or the motion could be assumed to take place in a two-dimensional plane. The calculation of aerodynamic force meant taking into account not only varying velocity (which, in turn, implied a set of differential equations) but also varying air density; the best method to find this was left to each student to determine.

In a question on orbital mechanics, the solution could be found numerically, via Gibbs' method, or geometrically via the application of Kepler's third law. In optical analysis, the student was to use images from the Sentinel satellites, taking into account vegetation, climate, cloud cover, etc. when selecting an area of study. This left a lot of room for exploration and encouraged imagination, rather than the simple application of the theory.

The staff at NAROM returned the assignments with detailed feedback, allowing each student to detect the weak spots of their work, and leaving open space for re-analysing conclusions. Thanks to these references, the students were able to improve their reporting, scheduling, and problem-solving skills, as well as the overall quality of their work.
During the pre-study course, the participants were in contact via an online social media group. This allowed them to get to know each other and gave the group a sense of community before the campaign even began. It also allowed each student to share their expertise, especially coming from different STEM areas. Many participants worked to help each other understand the assignments and troubleshoot problems. It also provided an easy way for them to stay in contact after the campaign, which had led to close collaboration among them.

\section{CAMPAIGN!}

The week-long rocket campaign at ASC was the apogee of the FaR! programme; there were lectures, lab work, teambuilding activities, excursions, and rocket launches.

The lectures complemented the pre-study material but also branched out to cover a wide variety of topics. Experts gave lectures on rockets, signal processing, the history of the ASC, balloon science, the space industry, the origin of the universe, and much more.

The goal of the campaign was to experience the process behind a rocket launch. The students assembled the payload, soldered sensors, simulated trajectories, built and launched two weather balloons. They took control of the NAROM launch procedure and ran through the checklist. The telemetry stations were manned by students, and others filled all the usual rocket range roles: Range Control, Principal Investigator, Payload Manager, Pad Supervisor, etc. After a few delays the rocket (named "Ballistic Rocket Experiment Inside the Troposphere") was launched successfully.

The rocket was prepared by four student teams, each with their own particular assignments and deadlines: Sensor Experiments, Telemetry and Data Readout, GPS and Simulations, and Payload.

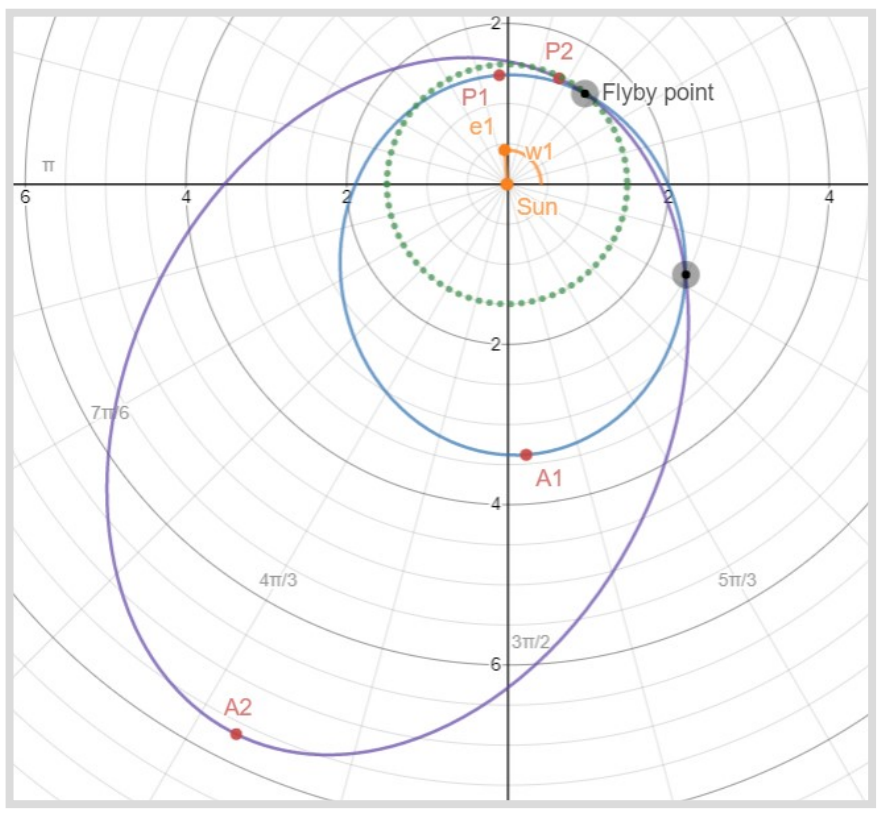

Fig. 2. Graph of the Rosetta spacecraft's orbits during 2009 Earth flyby, pre-study assignment, FaR! 2018-2019. 
The three members of the Payload team were responsible for the disassembly of the rocket, mounting of the sensors and transmitter, reassembly, and testing. Each sensor and plate, after being assembled, was tested and mounted on the payload. The technical details were well explained, and the NAROM staff were always available. However, in many cases there were no fixed instructions, no right answer. The location of each sensor, the design of the balloons, the useful parameters for sensor measurement: all these were the students' prerogative, and they in turn took responsibility for each of those decisions.

After the launch, the students spent the last day of the campaign doing intensive analysis of the information obtained from the rocket by the telemetry stations. There was no outline for this work, nor was there a required result. They were encouraged to select the data they wanted to analyse and pursue their own lines of research, following their own curiosity and interests. In the same spirit as in the pre-study assignments, the students did not have detailed instructions or expected results. Instead, they were asked to argument the results that their study provided.

Being free to select what they wanted to analyse allowed the participants to delve deeper into a particular topic and tackle all the challenges that came with each decision. Within that freedom, however, the analysis required the proper application of physics, maths, and research methods; this was often not visible at first glance. It also forced the students to make critical decisions and focus their efforts. With over 4 million data points to process, strategy was key.

Each group selected the data sets they wished to study and got to work: they organized and cleaned the data, interpolated, looked for correlations or contradictions, or compared the data to past missions and simulations. They reached plausible conclusions, or else reanalysed their method. The groups also shared their results and scripts, working together to get the most out of the limited time. The results of this analysis were processed and presented by each group of students at the end of the campaign and discussed with the experts from NAROM.

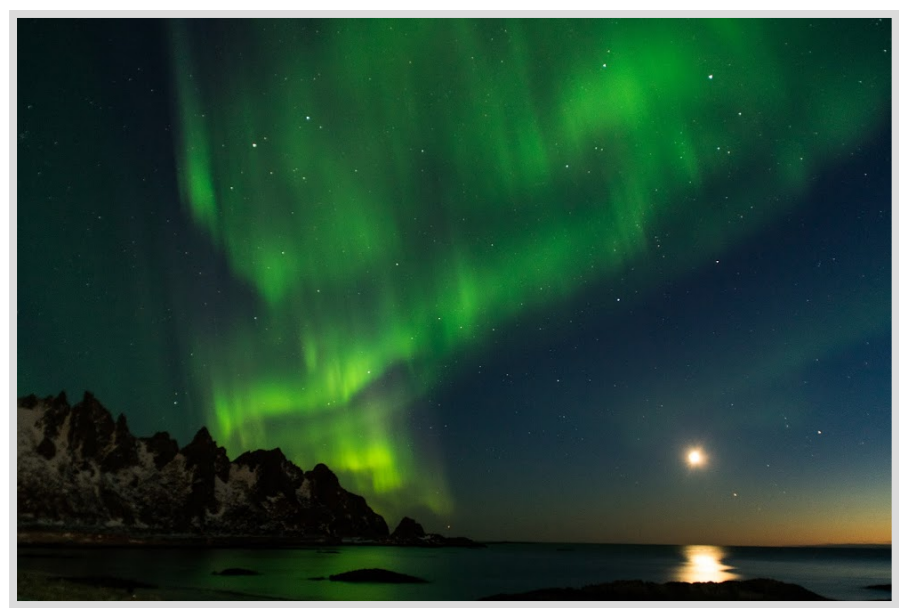

Fig. 3. Auroras at night over ASC. Source: Giovanni Bezze.

\section{EDUCATIONAL ASPECTS AND ACTIVE TRANSFER}

The Fly a Rocket! programme offered students a chance to experience a rocket launch first-hand. It was a memorable experience, but its importance goes beyond the cool factor.

As we have introduced in this short communication, FaR! made a deeper impact. Students learned the ins and outs of a launch campaign and gained technical expertise. They were also forced outside the protective blanket of their universities and given tasks without a unique correct answer. Through this approach, the students can catch a glimpse of how work is carried out in the aerospace industry.

The programme's importance, however, goes beyond informing them about their future; it teaches them how to become useful and proactive agents of that industry. It teaches them to become the kind of professionals that will spearhead innovation in a healthy and responsible way: learning to work as a team in spite of differences in background, meeting deadlines, building communication and leaving room for friendships to flourish. The space industry needs to become more innovative and self-aware; we the authors believe this human factor is vital in forging that future.

Specifically for aerospace students, we believe that the planning, manufacturing and launching a of rocket is an irreplaceable experience. While every university should aspire to provide this for their aerospace students, that is not always possible in smaller departments. Moreover, for students aiming to enter the space sector, this particular experience grants expertise that both space agencies and students will benefit from.

FaR! taught an important lesson: designing, calculating, integrating, and manufacturing a rocket is an engineering challenge that requires a team, working together. In addition, breaking down the construction of a rocket payload and assigning teams for its development is, we believe, an excellent analogy for any design or construction process in engineering.

Tasks must be detailed and allocated, which brings out the different profiles and areas of knowledge of the industry. As a result, the team members are forced to develop their own skills and affinities within the subject they are working on.

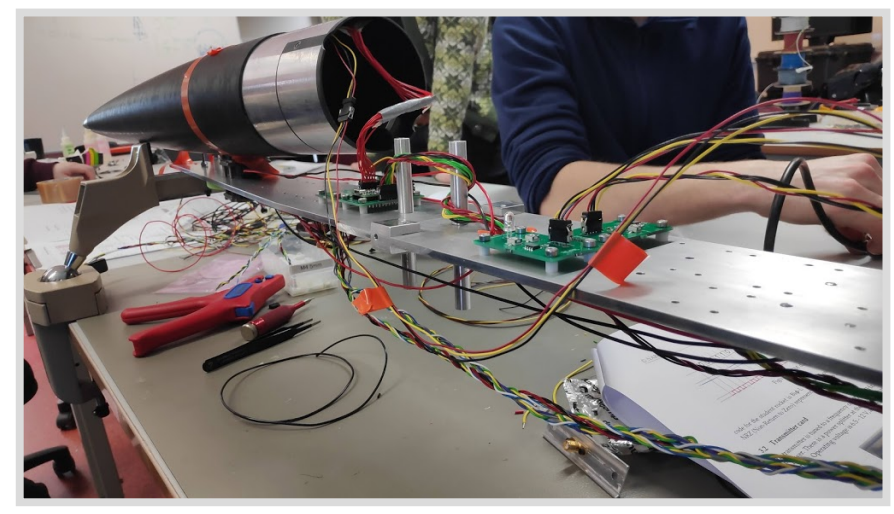

Fig. 4. Nosecone and payload assembly, NAROM lab at ASC. 
This approach is often lost in the university, as courses tend to provide a fair and uniform education to everyone, and graduates tend to find difficulties defining their niche. The lack of individualization has proven to be a common factor in the Spanish education system; graduates struggle when looking at job offers because the specific profiles from the industry don't match with what they feel they have learned at university.

Consequently, FaR! and similar programmes (like the Student Aerospace Challenge or the exploding Hackaton competitions) help to build students' confidence and allow them to overcome these limitations.

From the point of view of a growing department of a big university like ours, we believe that these kinds of international events are crucial. They teach students to participate and take on an active role, showing them the world outside their usual frontiers--both physically and professionally. There is a transfer of work methodology and knowledge between colleagues. They benefit others as well; the participating students brings the example of direct experience back to their classmates. This helps them expand their creativity and overcome their fears when applying, studying, and building their own projects.

A department in aerospace engineering must be in constant movement, learning and improving--especially if it aims to become a landmark in the European academic sector. This whole "movement" starts with the students and continues with the professors. When mentoring students to apply to European competitions and activities, the academic staff is forced to look away from their research for a moment. It puts the focus on the students and their projects. This helps them to keep in touch with the student body, and in some situations, to see an unexpected application of their research.

Finally, we believe the highlight of the programme was the creative aspect. It has been shown that open-ended assignments force students to break through the limitations their classical education has built around them, and to creatively explore all the possible solutions. These programmes teach them to find interconnections between different branches of their knowledge, to detect and understand their mistakes and to

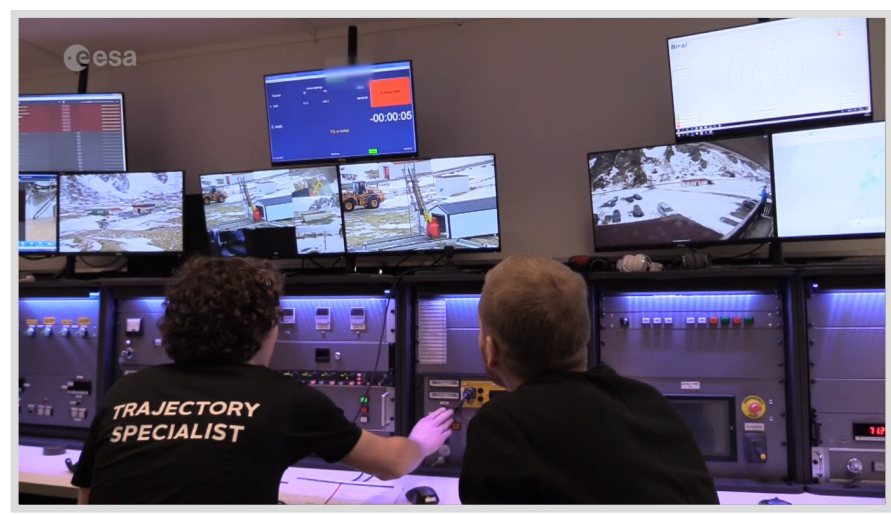

Fig. 5. The Pad Supervisor in the ASC bunkerhouse moments before launch. Source: ESA [1] listen to others' proposals; these skills are desirable, not only in a good scientist or engineer, but in any person.

Unfortunately, bachelor's degrees are often designed with little margin for these activities. Even if professors aim to develop new approaches, the increasing number of students per faculty member and the decreasing funding of public education [2] force the evaluation process to be highly restrictive. Students are usually fed information and asked to retain it until the exam. Even with assignments or projects, a lack of time or personal resources often hinders the creative process.

\section{CONCLUSION}

Fly a Rocket! was a comprehensive campaign in rocket technology that provides an active transfer between university education and the aerospace industry.

The pre-study course highlighted the importance of critical thinking in a very organic way. Students found that it challenged their grasp of the theory in a way formulaic university assignments cannot, and demanded creative problem-solving.

The campaign was technically rigorous. It required attention to detail and ultimately gave undergraduate students access to a ballistic rocket, with all the responsibility that comes with it. It also was an intensive teambuilding experience, as it required collaboration with the other participants--strangers from different cultures and backgrounds worked closely together during long days on a demanding project.

The FaR! programme and others like it are a key component in the education of future engineers and scientists. They fill the gap between theory and practice, exams and rocket launches, academia and professional life. In the rapidlyevolving space sector, it is crucial that we educate engineers and scientists that can face a completely new problem and ask themselves not just "How do we find the answer?" but first, "What exactly is the problem? What kind of answer do we want, and why? And in this pursuit, what should we take into account?" Repetition leaves no room for innovation.

\section{ACKNOWLEDGMENT}

A. Solá would like to thank the ESA Education Office for sponsoring her attendance to the symposium.

The authors want to thank NAROM, ASC, ESA, and the Norwegian Space Agency for the Fly a Rocket! programme.

\section{REFERENCES}

[1] ESA Education Office, Rocket flies for the $2^{\text {nd }}$ Cycle of the Fly a Rocket! Programme. European Space Agency, 12 April 2019. Retrieved from: https://www.esa.int/Education/Fly_A_Rocket/Rocket_flies_for_the_2nd _Cycle_of_the_Fly_a_Rocket!_programme

[2] E.B. Pruvot, T. Estermann, and V. Lisi, 2018 Public Funding Observatory Report. European University Association, 2019. Retrieved from: https://eua.eu/101-projects/586-public-funding-observatory.html

[3] L. Jackson et al, Fly a Rocket! Final Report, unpublished. 2019. 